\title{
Impaired Muscle Oxygenation During Incremental Cycle Exercise in COPD Patients Compared with Age-Matched Healthy Subjects
}

\author{
Yoshitaka Tateishi ${ }^{*}, 1,2,3$, Yohsuke Eguchi ${ }^{1,2}$, Yoshiki Tohyama ${ }^{1,2}$, Kazuto Hirata ${ }^{2}$ and \\ Shigeo Fujimoto ${ }^{1}$ \\ ${ }^{I}$ Department of Sports Medicine, Osaka City University, Graduate School of Medicine, Osaka, Japan \\ ${ }^{2}$ Department of Respiratory Medicine, Osaka City University, Graduate School of Medicine, Osaka, Japan \\ ${ }^{3}$ National Hospital Organization, Toneyama National Hospital, Osaka, Japan
}

\begin{abstract}
This study examined the dynamics of muscle oxygenation during exercise between chronic obstructive pulmonary disease (COPD) patients and age-matched healthy controls. Oxygen saturation of the vastus lateralis muscle $\left(\mathrm{SmO}_{2}\right)$ was measured during incremental cycle exercise in 11 patients with exercise intolerance below the anaerobic threshold (AT) workload (COPD-AT(-)), 11 patients with exercise intolerance above the AT workload (COPD-AT(+)), and 8 controls by using near-infrared spectroscopy. Despite lower peak workload in COPD patients than in controls, trough $\mathrm{SmO}_{2}$ in COPD-AT(-) patients was significantly lower than $\mathrm{SmO}_{2}$ at the AT workload in controls, and was the same level as trough $\mathrm{SmO}_{2}$ in COPD-AT(+) patients and trough $\mathrm{SmO}_{2}$ in controls. The decrease of $\mathrm{SmO}_{2}$ was correlated with forced expiratory volume in one second \% in COPD-AT $(+)$ patients, and with exercise-induced hypoxemia in COPD-AT(-) patients. In conclusion, muscle oxygenation status deteriorates more steeply during exercise in COPD patients than in age-matched controls. Such severe impairment of muscle oxygenation in COPD patients may be affected by the impairment of lung function caused by COPD.
\end{abstract}

Keywords: COPD, cardiopulmonary exercise testing, anaerobic threshold, vastus lateralis muscle, near-infrared spectroscopy, tissue oxygenation.

\section{INTRODUCTION}

Exercise intolerance is a common symptom of chronic respiratory disease. Chronic obstructive pulmonary disease (COPD), the commonest smoking-related disease, likely to be ranked fourth by 2020 in terms of burden of disease worldwide, has been especially thoroughly studied in this regard, focusing on the pathophysiology of exercise performance [1]. Because COPD primarily presents as airway narrowing caused by chronic inflammation, and alveolar destruction, exercise intolerance in COPD has been previously attributed exclusively to airflow limitation $[2,3]$. However, recent studies have identified dysfunction of the vastus lateralis muscle (VLm), a functional group of muscles active during systemic exercise such as cycling and walking, in COPD patients [4-9]. A preference for anaerobic metabolism of the VLm in COPD patients is suggested by decreased oxidative capacity of mitochondrial matrix enzymes [8] and phosphocreatinine breakdown [10] during exercise, and by the shifting of muscle fiber type [7]. Moreover, a tendency towards anaerobic metabolism evoked by exercise is suggested by the early onset of lactic acidosis in COPD patients $[6,11]$.

\footnotetext{
*Address correspondence to this author at the National Hospital Organization, Toneyama National Hospital, 5-1-1, Toneyama, Toyonaka, Osaka, 560-8552, Japan; Tel: +81-6-6853-2001; Fax: +81-6-6853-3127;

E-mail: tateishi@toneyama.go.jp
}

Near-infrared spectroscopy (NIRS) is a non-invasive technique that can measure intact tissue oxygenation using the differential absorption properties of oxygenated compared to deoxygenated forms of hemoglobin and myoglobin $([\mathrm{Hb}+\mathrm{Mb}])$ [12]. Recently, NIRS has been used to monitor oxygenation status of the working muscle during exercise, revealing that impairment patterns of muscle oxygenation are different depending on the workload in healthy humans [13]. During constant workload exercise on a bicycle, the deoxygenation signal of the VLm increases in relation to the decrease in oxygenation signal when the loading is above the anaerobic threshold (AT) [14]. This indicates that the oxygenation is strongly impaired in the exercising muscle, due to its increased oxygen demand. In contrast, the oxygenation and deoxygenation signals of VLm remain at a constant level when the loading is below the AT workload, indicating the leveling off of oxygen consumption by the exercising muscle [14, 15]. Incremental exercise, another common protocol of exercise testing, elicits different profiles of cardiopulmonary and metabolic responses. During incremental exercise using a cycle ergometer, the oxygenation signal decreases more steeply during exercise above the AT workload than during exercise below it [16, 17], confirming that AT is the crucial threshold at which oxygen delivery becomes insufficient to fulfill the increased oxygen demand of the exercising muscle. This impairment pattern of oxygenation of the working muscle is consistent with the physiological response of aerobic/anaerobic 
metabolism during exercise. That is, aerobic metabolism functions effectively to produce energy by completely oxidizing glycogen as well as by ß-oxidation of fatty acids under oxygen-replete conditions, whereas anaerobic metabolism is triggered by incomplete oxidation of glycogen as a less effective but thrifty way of energy production under conditions of insufficient oxygen delivery.

In contrast to the metabolic and histological analyses of the VLm in health, little is known about the dynamics of muscle oxygenation of the exercising VLm in COPD patients. Difficulties in studying the dynamics of muscle oxygenation in COPD patients may be attributed to the variation of AT level in association with exercise intolerance. In some patients, exercise intolerance is manifested by decreased oxygen consumption $\left(\mathrm{V}_{\mathrm{O} 2}\right)$ at the $\mathrm{AT}$ workload and by decreased peak $\mathrm{V}_{\mathrm{O} 2}$. However, in other patients, exercise capacity is also limited below the AT workload as shown by the lack of the AT point by the Vslope method [1, 18]. However, to the best of our knowledge, no studies have evaluated the degree of impairment of muscle oxygenation of VLm at AT workload and at peak workload separately during incremental exercise in COPD patients, nor compared the impairment patterns of muscle oxygenation between these patients and healthy subjects.

We hypothesized that oxygenation of the exercising VLm in COPD patients might be as or more severely impaired than in healthy subjects. We also hypothesized that the degree of muscle oxygenation impairment might be correlated with pulmonary function impairments and/or abnormal cardiopulmonary responses in COPD patients, and that the degree of muscle oxygenation impairment might be associated with different exercise-limiting factors, such as leg fatigue and dyspnea. Here, we compare muscle oxygen saturation $\left(\mathrm{SmO}_{2}\right)$ of the exercising VLm during incremental cycle exercise in relation to the cardiopulmonary responses in COPD patients categorized by exercise capacity with respect to their AT level, and age-matched healthy subjects.

\section{MATERIALS AND METHODOLOGY}

\section{Subjects}

Twenty-two patients with COPD and 8 age-matched healthy sedentary subjects (all male) were recruited in this studied. All participants were Japanese. The study was approved by the Institutional Review Board of Osaka City University, and all subjects gave their written informed consent to participate in the study. This study was entirely performed in outpatient clinics of Osaka City University Medical Hospital. Diagnosis of COPD was made according to the American Thoracic Society guidelines [19]. All patients had a smoking history of at least 20 pack-years. They were clinically stable without a history of acute exacerbation within at least 4 weeks. They received regular treatment using bronchodilators with inhaled anticholinergic drugs, oral theophylline, and inhaled short-acting and/or long-acting $\beta_{2}$ stimulants; however, none received corticosteroids. Patients with coronary heart disease and peripheral vascular disease were excluded from the study. None of them had radiological or clinical evidence of pulmonary congestion or right heart failure.
All patients belonged to the moderate to severe stages of $\mathrm{COPD}\left(\mathrm{FEV}_{1}, 30-80 \%\right.$ predicted) defined by the American Thoracic Society guideline [19]. We chose these stages of COPD patients because they were expected to undertake exercise completely enough to obtain cardiopulmonary response data during exercise in contrast to those at rest.

\section{Pulmonary Function Test and Arterial Blood Gas Analysis}

Forced vital capacity and $\mathrm{FEV}_{1}$ was measured in all study subjects using a Chestac-25F system (Chest, Tokyo, Japan). In COPD patients, residual volume (RV) and total lung capacity (TLC) were measured by helium dilution method using the same system. The diffusing capacity for carbon monoxide (TLco) was measured by the single-breath carbon monoxide method. RV, TLC, and TLco were measured at least twice. Arterial blood gas was drawn at rest in COPD patients, and analyzed using a blood gas analyzer (ABLTM520 Blood Gas System; Radiometer Medical A/S, Copenhagen, Denmark).

\section{Exercise Protocol}

All study subjects underwent cardiopulmonary exercise testing on an upright cycle ergometer (EM840; SIEMENS, Munich, Germany). The protocol consisted of unloaded pedaling at 0 Watt for $3 \mathrm{~min}$ followed by 10 Watt ramp increments every minute until symptomatic limitation. Pulmonary oxygẹn consumption $\left(\mathrm{V}_{\mathrm{O} 2}\right)$, pulmonary carbon dịoxide output $\left(\mathrm{V}_{\mathrm{CO} 2}\right)$, expired minute ventilation volume $\left(\mathrm{V}_{\mathrm{E}}\right)$ and respiratory rate $(\mathrm{RR})$ were measured continuously using a respiratory monitor (Respiromonitor AE-300; Minato Medical Science, Osaka, Japan). Heart rate was monitored using standard electrocardiographic equipment. Percutaneous oxygen saturation $\left(\mathrm{SpO}_{2}\right)$ was measured continuously through the fingertip using pulse oximeter (Pulse oximeter 520-US; Criticare System, Waukesha, WI). AT point was determined by the V-slope plot $\left(\mathrm{V}_{\mathrm{CO} 2}\right.$ as a function of $\left.\mathrm{V}_{\mathrm{O} 2}\right)$ [1]. Eleven patients terminated exercise below the AT workload (COPD-AT(-)), and the rest of the patients did above the AT workload (COPD-AT $(+))$. Exercise-induced hypoxemia $(\mathrm{EIH})$ was evaluated by the difference. of $\mathrm{SpO}_{2 \text { peak }}$ and $\mathrm{SpO}_{2 \text { rest }}$ divided by the difference of peak $\mathrm{V}_{\mathrm{O} 2}$ $\left(\mathrm{V}_{\mathrm{O} 2 \text { peak }}\right)$ and rest $\mathrm{V}_{\mathrm{O} 2}$ at rest $\left(\mathrm{V}_{\mathrm{O} 2 \text { rest }}\right)$.

Patients were questioned at the end of the exercise about the symptomatic exercise-limiting factors, i.e. dyspnea and leg fatigue. The degree of these symptoms was evaluated by the Borg scale. A symptom of which score was $>=9$ (extreme or maximal symptom) was determined as an exerciselimiting factor.

\section{Measurement of Muscle Oxygen Saturation by NIRS}

Oxygen saturation of the vastus lateralis muscle $\left(\mathrm{SmO}_{2}\right)$ was monitored by the spatially-resolved NIRS instrument, NIRO200 (Hamamatsu Photonics, Hamamatsu, Japan). The mechanical structure and the principle of the measurement were described previously [20]. In brief, the instrument consists of the probe, the measurement unit, and the display unit. The probe has one emitter and one detector. The light of three wavelengths $(775,810$, and $850 \mathrm{~nm})$ is irradiated from the emitter, and sensed by the detector which is $4 \mathrm{~cm}$ distant from the emitter. The concentration ratio of $\mathrm{oxy}[\mathrm{Hb}+\mathrm{Mb}]$ to total[ $\mathrm{Hb}+\mathrm{Mb}]$ is computed from light 
attenuation using the photon diffusion equation. NIRS can not distinguish signals by hemoglobin from those by myoglobin because of the identical spectral characteristics. Therefore, the signals of NIRS are considered to reflect the whole status of local oxygenation of the muscle derived from both hemoglobin and myoglobin.

The probe was positioned on the lower one-third of the right vastus lateralis muscle. $\mathrm{SmO}_{2}$ was measured continuously every 2 seconds during exercise. The decrease of $\mathrm{SmO}_{2}\left(\Delta \mathrm{SmO}_{2}\right)$ was calculated by the difference of maximal value of $\mathrm{SmO}_{2}\left(\mathrm{SmO}_{2}\right.$ at rest or during warm-up period) from minimal value of $\mathrm{SmO}_{2}$ at peak workload.

\section{Statistical Analysis}

All values were presented as mean \pm SD. Statistical analyses were performed using Stat View 5.0 software (Stat View, Inc.; Berkeley, CA). Data of age, body mass, pulmonary function, cardiopulmonary exercise testing, and muscle oxygen saturation were compared by Kruskal-Wallis test among study groups. When the difference was significant, Scheffé test was applied as a post-hoc test. Data of pulmonary function test which were not determined in healthy subjects were compared by Mann-Whitney's U test between COPD-AT(-) patients and COPD-AT(+) patients. Correlation analysis was performed using Spearman's rank correlation test between the decrease of $\mathrm{SmO}_{2}$ and pathophysiological parameters including anthropometry, pulmonary function, or cardiopulmonary data in COPD patients. Significant difference was set at $\mathrm{p}<0.05$.

\section{RESULTS}

Study subjects' characteristics are shown in Table $\mathbf{1 .}$ Body mass index was significantly lower than in healthy subjects in COPD-AT(-) patients $(\mathrm{p}=0.007)$ but not COPD$\mathrm{AT}(+)$ patients. There were no significant differences in pulmonary function and arterial blood gas data between COPD-AT(-) and COPD-AT(+) patients.

Results of cardiopulmonary exercise testing are shown in Table 2. Peak work rate and peak $\mathrm{V}_{\mathrm{O} 2}$ was significantly lower in COPD-AT(-) patients than in COPD-AT(.+) patients or healthy subjects. Peak ventilatory volume $\left(\mathrm{V}_{\text {Epeak }}\right)$ and peak tidal volume $\left(\mathrm{TV}_{\text {peak }}\right)$ was significantly lower in both COPD groups than in healthy subjects with the same degree of peak respiratory rate, indicating a shallow breathing pattern in COPD patients. Although peak $\mathrm{SpO}_{2}$ tended to be lower in both COPD groups (but not significantly), $\Delta \mathrm{SpO}_{2}$ $/ \Delta \mathrm{V}_{\mathrm{O} 2}$ was severely lower in COPD-AT(-) patients than in COPD-AT $(+)$ patients, indicating severe exercise-induced hypoxemia (EIH) in COPD-AT(-) patients. EIH was absent in healthy subjects.

Changes of $\mathrm{SmO}_{2}$ during exercise are shown in Fig. (1). At rest, there were no significant differences in $\mathrm{SmO}_{2}$ among the study groups $(56.5 \pm 4.9 \%, 59.2 \pm 3.8 \%, 59.6 \pm 5.5 \%$ in COPD-AT(-), COPD-AT( $(+)$, and healthy subjects, respectively). On 3-minute unloaded pedaling, $\mathrm{SmO}_{2}$ tended to increase slightly to $61.2 \pm 4.2 \%$ and $63.6 \pm 6.0 \%$ in $\mathrm{COPD}-\mathrm{AT}(+)$ patients and in healthy subjects, respectively. In contrast, $\mathrm{SmO}_{2}$ tended to decrease slightly in COPD-AT() patients to $54.9 \pm 4.4 \%$ in association with significant increase of deoxy[Hb+Mb] level. This represented a significant difference in $\mathrm{SmO}_{2}$ compared with COPD-AT( $(+)$ patients and healthy subjects (COPD-AT(-) vs COPD-AT $(+)$, $\mathrm{p}=0.018$; COPD-AT(-) $v s$ healthy subjects, $\mathrm{p}=0.0025)$. Trough $\mathrm{SmO}_{2}$ in COPD-AT(-) was significantly lower than AT workload- $\mathrm{SmO}_{2}$ in healthy subjects $(48.5 \pm 6.1 \%$ and $56.8 \pm 6.3 \%$, respectively; $p=0.024)$ in association with significantly progressive increase of deoxy[Hb+Mb] level and with significantly lower oxy[Hb+Mb] level. The level of trough $\mathrm{SmO}_{2}$ was the same degree among COPD-AT(-), COPD-AT(+), and healthy subjects (COPD-AT(+) $49.9 \pm$ $6.3 \%$, healthy subjects $50.2 \pm 6.2 \%$, COPD-AT(-) vs COPD$\mathrm{AT}(+) ; \mathrm{p}=0.873$, COPD-AT(-) vs healthy subjects; $\mathrm{p}=$ $0.845)$.

We also investigated the correlation between muscle desaturation and pathophysiological parameters in COPD patients, and found that the decrease of $\mathrm{SmO}_{2}\left(\Delta \mathrm{SmO}_{2}\right)$ was correlated with $\Delta \mathrm{SpO}_{2} / \Delta \mathrm{V}_{\mathrm{O} 2}(\mathrm{EIH})(\mathrm{r}=0.682, \mathrm{p}=0.031)$ in COPD-AT(-) patients, and with $\mathrm{FEV}_{1} / \mathrm{FVC}$ in COPD-AT(+)

Table 1. Characteristics of Study Subjects

\begin{tabular}{|c|c|c|c|}
\hline & COPD-AT(-) & COPD-AT(+) & Healthy Subjects \\
\hline $\mathrm{N}$ & 11 & 11 & 8 \\
\hline Age, years & $64 \pm 5$ & $69 \pm 9$ & $65 \pm 8$ \\
\hline BMI & $20.1 \pm 1.7^{*}$ & $21.8 \pm 2.7$ & $23.9 \pm 2.5$ \\
\hline $\mathrm{FEV}_{1}, \%$ of predicted & $49.1 \pm 13.1^{*}$ & $51.6 \pm 15.8^{*}$ & $94.0 \pm 17.2$ \\
\hline $\mathrm{FEV}_{1} / \mathrm{FVC}, \%$ & $49.0 \pm 14.8^{*}$ & $45.9 \pm 13.7^{*}$ & $79.5 \pm 6.7$ \\
\hline TLco, $\%$ of predicted & $78.1 \pm 20.3$ & $81.0 \pm 18.1$ & ND \\
\hline $\mathrm{TLco} / \mathrm{V}_{\mathrm{A}}, \%$ of predicted & $85.2 \pm 21.6$ & $89.7 \pm 20.7$ & ND \\
\hline RV/TLC, $\%$ of predicted & $45.9 \pm 4.0$ & $42.4 \pm 7.0$ & ND \\
\hline $\mathrm{SpO}_{2}$ rest, $\%$ & $97.8 \pm 1.0$ & $97.1 \pm 1.0$ & $98.4 \pm 0.7$ \\
\hline $\mathrm{PaO}_{2}$ rest, $\mathrm{mmHg}$ & $76.7 \pm 8.4$ & $77.7 \pm 4.9$ & ND \\
\hline $\mathrm{PaCO}_{2}$ rest, $\mathrm{mmHg}$ & $38.9 \pm 3.9$ & $41.0 \pm 1.9$ & ND \\
\hline
\end{tabular}

Values represent mean \pm SD. COPD-AT(-) = COPD patients who terminated exercise below the anaerobic threshold workload; COPD-AT $(+)=$ COPD patients who terminated exercise above the anaerobic threshold workload; BMI = body mass index; TLco = lung diffusion capacity for carbon monoxide; $\mathrm{RV} / \mathrm{TLC}=$ the ration of residual volume to total lung capacity; $\mathrm{SpO}_{2}=$ percutaneous oxygen saturation. $*=$ significantly different from healthy subjects. ND = not determined. 
Table 2. Results of Cardiopulmonary Exercise Testing in Study Subjects

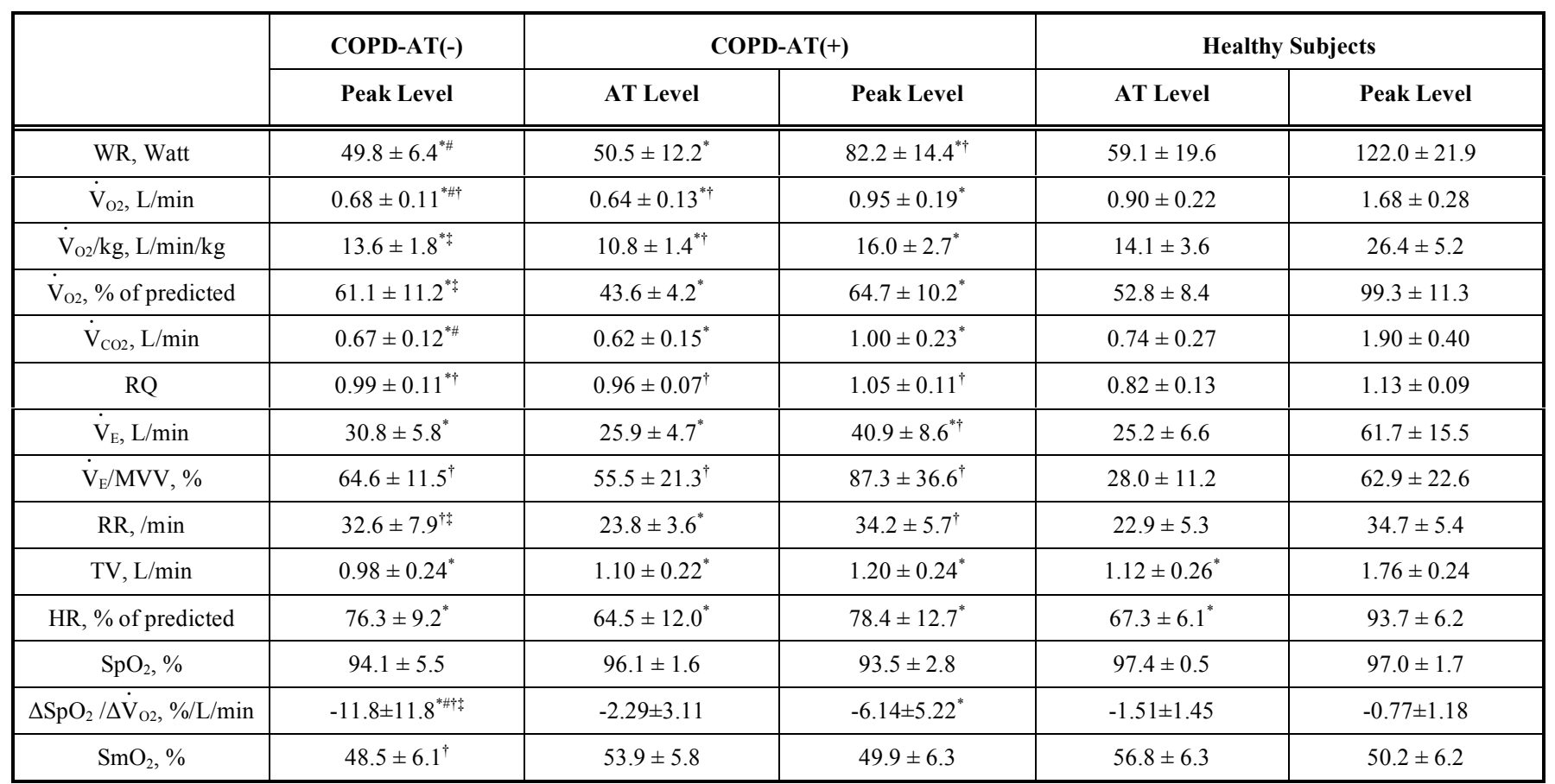

Values represent mean $\pm \mathrm{SD}$. $\mathrm{SmO}_{2}$ value at peak level is indicated as a maximum reduction (trough) of $\mathrm{SmO}_{2}$. COPD-AT(-) $=\mathrm{COPD}$ patients who terminated exercise below the anaerobic threshold workload; COPD-AT $(+)=\mathrm{COPD}$ patients who terminated exercise above the anaerobic threshold workload; $\mathrm{AT}=$ anaerobic threshold; $\mathrm{WR}=$ work rate; $\dot{\mathrm{V}}_{\mathrm{O} 2}=$ pulmonary oxygen consumption; $\mathrm{V}_{\mathrm{CO} 2}=$ pulmonary carbon dioxide output; $\mathrm{RQ}=$ respiratory quotient; $\mathrm{V}_{\mathrm{E}}=$ minute ventilation volume; $\mathrm{MVV}=$ maximum ventilatory volume (= $\left.35 \times \mathrm{FEV}_{1}\right) ; \mathrm{RR}=$ respiratory rate; $\mathrm{TV}=$ tidal volume; $\mathrm{HR}=$ heart rate; $\mathrm{SpO}_{2}=$ percutaneous oxygen saturation; $\Delta \mathrm{SpO}_{2} / \Delta \dot{\mathrm{V}}_{\mathrm{O} 2}=$ the decrease of SpO $\mathrm{O}_{2}$ in relation to the increase in pulmonary oxygen consumption. ${ }^{*}=$ significantly different from healthy subjects at peak level; ${ }^{*}=$ significantly different from $\mathrm{COPD}$-AT $(+)$ at peak level; ${ }^{\dagger}=$ significantly different from healthy subjects at AT level; ${ }^{*}=$ significantly different from COPD-AT $(+)$ at AT level.

patients $(\mathrm{r}=0.638, \mathrm{p}=0.043)$ (Fig. 2). There was no correlation between $\Delta \mathrm{SmO}_{2}$ and any other items of anthropometry, pulmonary function, or cardiopulmonary data.

Furthermore, we investigated differences in the degree of muscle desaturation between COPD subgroups categorized by symptomatic exercise-limiting factors, such as leg fatigue and dyspnea (Table 3). A subgroup of COPD-AT(-) who terminated exercise due to dyspnea displayed lower peak tidal volume than other COPD subgroups at peak workload, with a similar level of muscle desaturation.

\section{DISCUSSION}

In healthy subjects, submaximal exercise evokes desaturation of the working muscle because muscle oxygenation is impaired due to excessive oxygen demand relative to oxygen delivery capacity to the working muscle. This leads to the predominance of anaerobic metabolism for energy production. However, it is not known whether the impairment patterns of muscle oxygenation caused by submaximal exercise are different in COPD patients with exercise intolerance and healthy subjects. We demonstrated in this study that, despite significantly reduced peak workload in COPD patients, $\mathrm{SmO}_{2}$ decreased to the same level in both COPD-AT(-) patients and COPD-AT(+) patients at submaximal exercise levels as in age-matched healthy subjects. We also demonstrated that the decrease of $\mathrm{SmO}_{2}$ was correlated with EIH and airflow limitation in COPD-AT(-) patients and COPD-AT $(+)$ patients, respectively. These results indicate that exercising muscle becomes desaturated in COPD patients as severely as in healthy subjects exercising above the AT workload, and that muscle desaturation is related to pulmonary function impairments, such as ventilatory and gas exchange disorders. Furthermore, we characterized the COPD patients who terminated exercise below the AT level due to dyspnea as having a markedly shallow breathing pattern, with a similar level of muscle desaturation as in the other COPD subgroups.

Previous studies have shown that the impairment patterns of muscle oxygenation monitored by NIRS correlate closely with muscle energy metabolism during exercise [13-15, 17, 21]. Tissue hypoxia is known to inhibit protein synthesis and to lower gene expression of the MHC isoform, thereby it decreases muscle mass and alters the composition of the muscle fiber type [7, 22, 23]. Based on this histological change and biochemical abnormalities such as decreased capacity of mitochondrial enzymes [8, 24], muscle metabolism becomes preferentially anaerobic in COPD patients as demonstrated by the early lactic acidosis occurring during exercise $[6,11]$. Our finding of identical peak $\mathrm{SmO}_{2}$ level in COPD patients and healthy subjects suggests that the level of muscle desaturation in COPD patients at peak workload corresponds to that in healthy subjects exercising above the anaerobic threshold. Therefore, tissue hypoxia is considered to occur quite easily during daily physical movement in COPD patients. In addition to the identical level of trough $\mathrm{SmO}_{2}$, the data of significantly higher peak respiratory quotient in COPD-AT(-) compared with AT level in healthy subjects suggests that the pattern of 

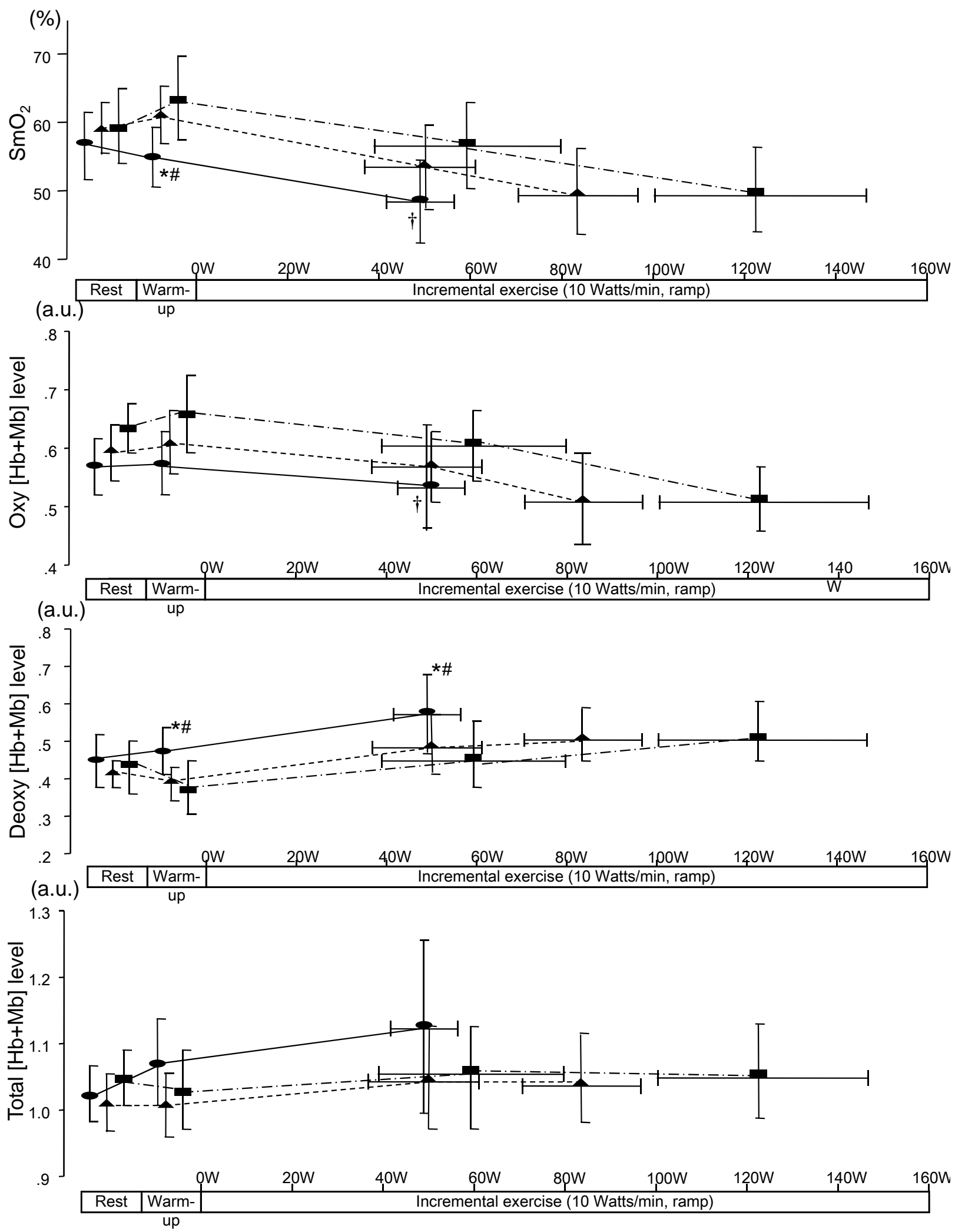

Fig. (1). Dynamics of muscle oxygenation during incremental cycle exercise including data of oxygen saturation of the vastus lateralis muscle $\left(\mathrm{SmO}_{2}\right)$, oxygenated, deoxygenated, and total [hemoglobin + myoglobin] levels. Circle $=$ patients with COPD whose exercise capacity was below the AT workload (COPD-AT(-)); triangle = patients with COPD whose exercise capacity was above the AT workload $(\mathrm{COPD}-\mathrm{AT}(+))$; square $=$ age-matched healthy subjects. Bars represent mean $\pm \mathrm{SD} .{ }^{*}=$ significantly different from healthy subjects after $3-$ min unloaded pedaling; ${ }^{*}=$ significantly different from COPD-AT $(+)$ after 3-min unloaded pedaling; ${ }^{\dagger}=$ significantly different from healthy subjects at AT level. 
(a)

COPD-AT(-)

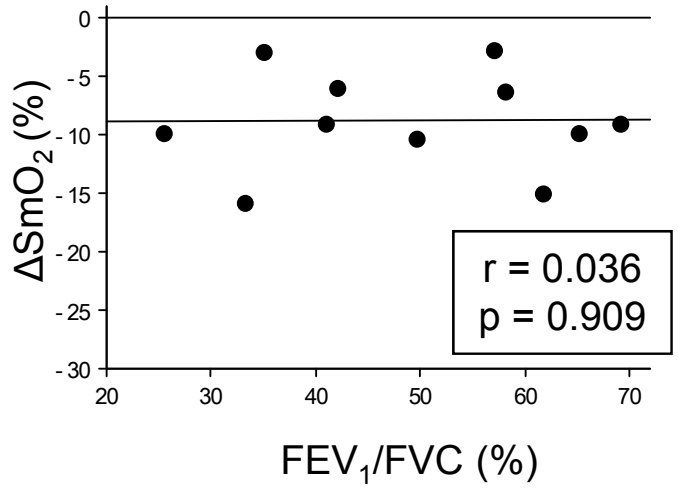

COPD-AT $(+)$

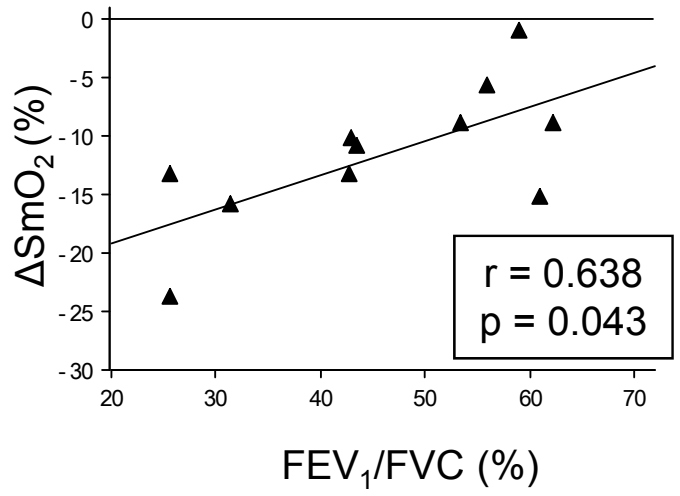

Healthy subjects

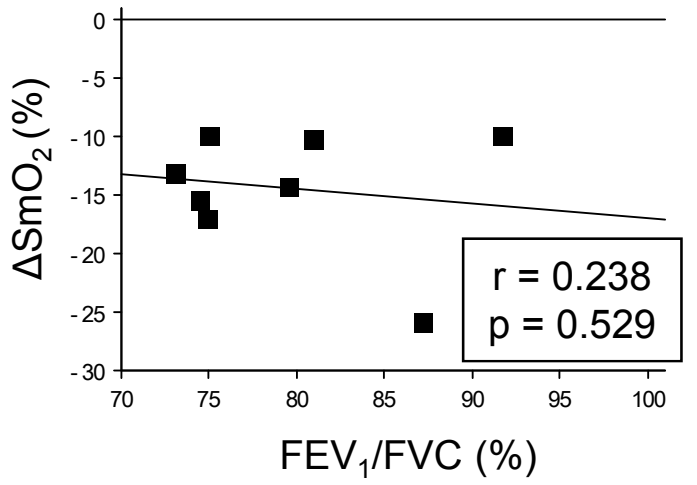

(b)

COPD-AT(-)

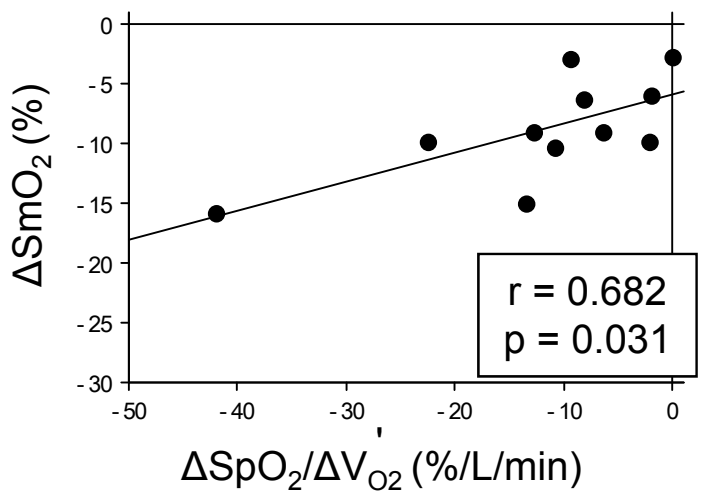

COPD-AT $(+)$

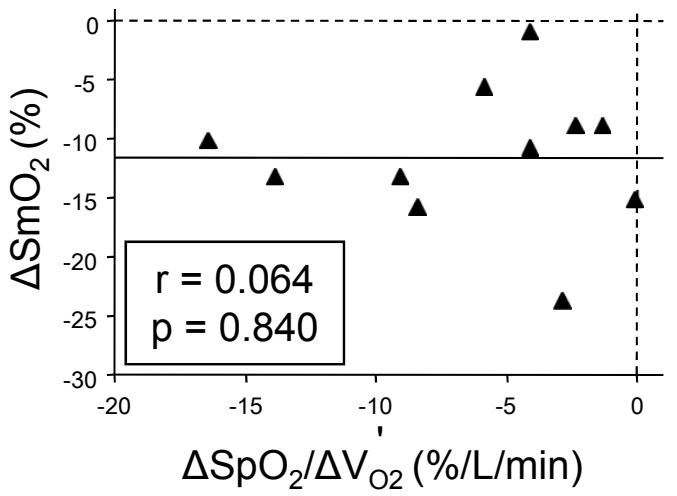

Healthy subjects

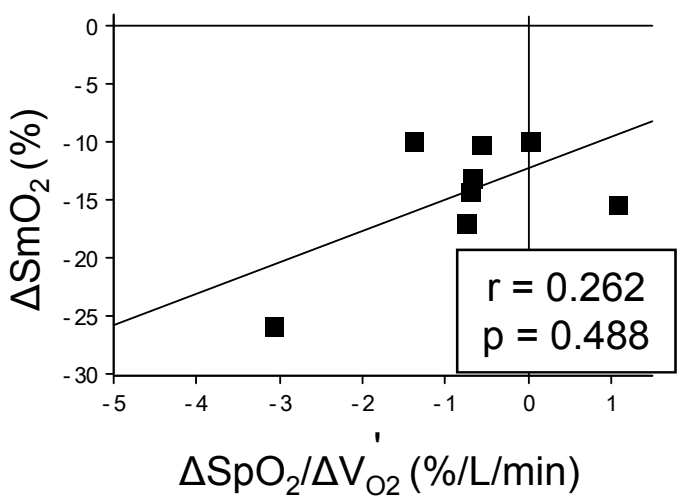

Fig. (2). Correlation of the decrease of $\mathrm{SmO}_{2}\left(\Delta \mathrm{SmO}_{2}\right)$ with $\mathrm{FEV}_{1} / \mathrm{FVC}$ (a) and with the decrease of $\mathrm{SpO}_{2}$ in relation to the increase in pulmonary oxygen consumption $\left(\left(\Delta \mathrm{SpO}_{2} / \Delta \mathrm{V}_{\mathrm{O} 2}\right)(\mathbf{b})\right.$ in study groups.

muscle metabolism is quite different between COPD patients with absence of AT point by the V-slope method and healthy subjects with incomplete loading of exercise below anaerobic threshold level. Failure to identify an AT point in COPD-AT(-) patients by the V-slope plot may be explained by such a low work rate of the AT that the dynamics of gas exchange at the start of exercise already reflect the presence of a lactic acidosis. We consider that $\mathrm{SmO}_{2}$ is a satisfactory parameter that reflects the patterns of muscle energy metabolism. Similar to ours, some previous studies measured muscle oxygen saturation during incremental cycle exercise in COPD patients $[25,26]$. These studies compared $\mathrm{SmO}_{2}$ only at peak workload but not at the AT workload, and therefore they failed to find any significance in the steep decrease of $\mathrm{SmO}_{2}$ in COPD patients compared with healthy subjects. We propose that muscle metabolism in COPD patients exercising under a low workload may correspond to the anaerobic metabolism above the AT workload in healthy controls, rather than their aerobic metabolism below the AT.

To our knowledge, this is the first study to show a correlation between the decrease of $\mathrm{SmO}_{2}$ and pulmonary function impairments in COPD patients. The data implies the possible involvement of respiratory dysfunction of COPD on 
Table 3. Characteristics of Cardiopulmonary Response in COPD Patients Classified by Symptomatic Exercise-Limiting Factors

\begin{tabular}{|c|c|c|c|c|}
\hline & \multicolumn{2}{|c|}{ COPD-AT(-) } & \multicolumn{2}{|c|}{ COPD-AT $(+)$} \\
\hline & Dyspnea & Leg Fatigue & Dyspnea & Leg Fatigue \\
\hline $\mathrm{N}$ & 7 & 4 & 7 & 4 \\
\hline $\mathrm{FEV}_{1}, \%$ of predicted & $52.5 \pm 15.5$ & $43.0 \pm 4.5$ & $48.7 \pm 13.6$ & $56.6 \pm 20.4$ \\
\hline $\mathrm{FEV}_{1} / \mathrm{FVC}, \%$ & $55.2 \pm 14.5$ & $37.8 \pm 4.4$ & $47.1 \pm 12.1$ & $43.9 \pm 18.0$ \\
\hline TLco, $\%$ of predicted & $85.0 \pm 14.5$ & $77.9 \pm 37.4$ & $86.8 \pm 18.3$ & $67.5 \pm 8.6$ \\
\hline BMI & $21.0 \pm 1.5$ & $18.6 \pm 0.7$ & $22.2 \pm 3.4$ & $21.2 \pm 1.6$ \\
\hline Peak WR, Watt & $47.3 \pm 5.7$ & $54.3 \pm 5.3$ & $84.3 \pm 14.2$ & $78.5 \pm 16.0$ \\
\hline Peak $\mathrm{V}_{\mathrm{O} 2}, \mathrm{~L} / \mathrm{min}$ & $0.66 \pm 0.10$ & $0.72 \pm 0.12$ & $0.94 \pm 0.19$ & $0.97 \pm 0.22$ \\
\hline Peak $\dot{\mathrm{V}}_{\mathrm{O} 2} / \mathrm{kg}, \mathrm{L} / \mathrm{min} / \mathrm{kg}$ & $13.0 \pm 1.9$ & $14.8 \pm 1.0$ & $15.8 \pm 2.0$ & $16.3 \pm 4.0$ \\
\hline Peak $\mathrm{V}_{\mathrm{O} 2}, \%$ of predicted & $59.1 \pm 12.5$ & $64.7 \pm 10.1$ & $65.1 \pm 6.5$ & $64.0 \pm 16.2$ \\
\hline Peak $\mathrm{V}_{\mathrm{CO} 2}, \mathrm{~L} / \mathrm{min}$ & $0.65 \pm 0.14$ & $0.70 \pm 0.09$ & $0.97 \pm 0.19$ & $1.06 \pm 0.32$ \\
\hline Peak RQ & $0.98 \pm 0.07$ & $0.99 \pm 0.13$ & $1.09 \pm 0.15$ & $1.03 \pm 0.09$ \\
\hline Peak $V_{E}, L / m i n$ & $30.0 \pm 6.5$ & $32.2 \pm 5.0$ & $41.7 \pm 9.5$ & $39.6 \pm 8.0$ \\
\hline Peak RR, L/min & $35.9 \pm 8.0$ & $26.7 \pm 3.3$ & $35.2 \pm 7.0$ & $32.6 \pm 1.6$ \\
\hline Peak TV, L/min & $0.85 \pm 0.18^{*}$ & $1.21 \pm 0.13$ & $1.19 \pm 0.22$ & $1.21 \pm 0.23$ \\
\hline Peak HR, $\%$ of predicted & $77.6 \pm 12.6$ & $75.5 \pm 7.8$ & $79.4 \pm 10.8$ & $77.8 \pm 14.4$ \\
\hline Peak $\mathrm{SpO}_{2}, \%$ & $95.4 \pm 3.4$ & $91.2 \pm 7.9$ & $94.1 \pm 2.7$ & $92.5 \pm 3.1$ \\
\hline$\Delta \mathrm{SpO}_{2} / \Delta \dot{\mathrm{V}}_{\mathrm{O} 2}, \% / \mathrm{L} / \mathrm{min}$ & $-10.0 \pm 7.56$ & $-15.0 \pm 18.3$ & $-6.03 \pm 6.38$ & $-6.34 \pm 3.06$ \\
\hline Peak $\mathrm{SmO}_{2}, \%$ & $49.1 \pm 4.6$ & $47.5 \pm 8.9$ & $49.3 \pm 6.8$ & $51.0 \pm 6.2$ \\
\hline$\Delta \mathrm{SmO}_{2}, \%$ & $-9.0 \pm 3.7$ & $-8.4 \pm 5.5$ & $-12.0 \pm 6.9$ & $-11.0 \pm 4.5$ \\
\hline
\end{tabular}

Values represent mean \pm SD. COPD-AT(-) $=$ COPD patients who terminated exercise below the anaerobic threshold workload; COPD-AT $(+)=$ COPD patients who terminated exercise above the anaerobic threshold workload; TLco = lung diffusion capacity for carbon monoxide; $\mathrm{BMI}=$ body mass index; $\mathrm{AT}=$ anaerobic threshold; $\mathrm{WR}=$ work rate; $\dot{\mathrm{V}}_{\mathrm{O} 2}=$ pulmonary oxygen consumption; $\dot{\mathrm{V}}_{\mathrm{CO} 2}=$ pulmonary carbon dioxide output; $\mathrm{RQ}=$ respiratory quotient; $\dot{\mathrm{V}}_{\mathrm{E}}=$ minute ventilation volume; $\mathrm{RR}=$ respiratory rate, $\mathrm{TV}=$ tidal volume; $\mathrm{HR}$ $=$ heart rate; $\mathrm{SpO}_{2}=$ percutaneous oxygen saturation; $\Delta \mathrm{SpO}_{2} / \Delta \mathrm{V}_{\mathrm{O} 2}=$ the decrease of $\mathrm{SpO}_{2}$ in relation to the increase in pulmonary oxygen consumption. * ${ }^{*}$ significantly different from other groups.

muscle oxygenation impairment. The difference of correlation factor between COPD-AT(-) and COPD-AT(+) patients is considered to be due to the different steepness of the decrease of $\mathrm{SpO}_{2}$ in relation to the increase in workload $\left(\Delta \mathrm{SpO}_{2} / \Delta \mathrm{V}_{\mathrm{O} 2}\right)$. COPD-AT(-) is characterized by the steeper decrease of $\mathrm{SpO} 2$ with the increase of workload compared with COPD-AT(+). In COPD-AT(-) patients, the correlation between $\Delta \mathrm{SmO}_{2}$ and $\Delta \mathrm{SpO}_{2} / \Delta \mathrm{V}_{\mathrm{O} 2}$ suggests that the degree of muscle deoxygenation is associated with the decrease of oxygen delivery by the efferent circulation accompanied by the increase in workload. On the other hand, in COPD$\mathrm{AT}(+)$ patients, the correlation between $\Delta \mathrm{SmO}_{2}$ and $\mathrm{FEV}_{1}$ suggests that the degree of muscle deoxygenation is associated with the severity of expiratory airflow limitation. Airflow limitation is regarded as a main etiology of COPD [19]. We could not confirm in this study whether the involvement of ventilator insufficiency in muscle oxygenation impairment in COPD-AT $(+)$ is in a direct or an indirect manner, there are several reports suggesting the possible relationship between ventilation and muscle oxygenation. Overloading of ventilatory muscle diverts blood flow from the exercising locomotor muscle to ventilatory muscle, and simultaneously increases secretion of norepinephrine [27]. In COPD patients, as demonstrated by lower peak tidal volume in COPD-AT $(+)$ than in healthy subjects, such an ineffective 'rapid and shallow breathing pattern' may increase ventilatory muscle loading, possibly resulting in the redistribution of blood flow and vasoconstriction of locomotor muscle by enhanced sympathetic activity. The influence of ventilatory insufficiency on muscle oxygenation is also supported by a recent study of the effect of unloading the ventilatory muscle [28], showing that proportional assist ventilation during exercise improves oxygenation and decreases exerciseinduced lactate production by the locomotor muscle in COPD patients without significantly increasing systemic oxygen delivery.

Dyspnea and exercise intolerance are important predictors of outcome in COPD patients [29]. As characterized in this study, COPD patients who terminate exercise below the AT workload due to dyspnea have a shallow breathing pattern with poor exercise capacity and a similar decrease of $\mathrm{SmO}_{2}$. Since there is no prominent difference in resting pulmonary function and anthropometry among COPD patients, such breathing pattern may be attributed to the dynamic hyperinflation, the ventilatory disorder characteristically induced by exercise in COPD patients. In addition to that, psychosomatic reaction to dyspnea feeling may be also involved in this breathing pattern; i.e. high susceptibility to dyspnea feeling, which is 
commonly found in COPD patients, may exaggerate the effort to increase respiratory rate followed by exacerbating dead space ventilation. We propose that respiratory physicians should purposefully seek to identify this COPD subgroup by means of cardiopulmonary exercise testing with careful management and subsequent follow-up.

Our finding of significant differences in $\mathrm{SmO}_{2}$ after 3min unloaded pedaling is intriguing. In healthy subjects, the oxygenation signal remains at a constant level during unloaded pedaling, slightly higher than at rest $[17,30]$. On the other hand, lower $\mathrm{SmO}_{2}$ value during warm-up pedaling reflects delayed hemodynamic response of the working muscle by an NIRS study in patients with heart failure, suggesting the disturbance of dilation of intamuscular capillaries followed by hyperemia [30]. Moreover, as demonstrated by the delay of time constant after constant workload exercise in COPD patients [31, 32], local muscle oxygenation is disturbed in association with delayed cardiopulmonary response of promoting local circulation of the working muscle. This deteriorated response may be speculated by the histological change such as decreased muscle capillaries, which is closely related to enhanced lactate production during exercise and increased muscle fatigability [33]. Therefore, the difference of lower $\mathrm{SmO}_{2}$ level in COPD patients may reflect the different degree of delayed vascular response of promoting local circulation, which may be based on the differential level of the preference of anaerobic muscle metabolism among COPDAT(-), COPD-AT(+), and healthy subjects. As a local molecular mechanism, intramuscular milieu such as by sympathetic nervous activity, adenosine, endothelial cell function, conductive vascular dilatation, and intramuscular mechanical pressure regulate constant oxygen perfusion through vasodilatation of the muscle capillaries [34, 35]. For example, interstitial and plasma adenosine stimulate production of vasodilatory compounds such as nitric oxide and prostacyclin in human skeletal muscle [36]. Such bioactive molecule-mediated vascular response may be involved in the difference of muscle oxygenation level among COPD patients. $\mathrm{SmO}_{2}$ after warm-up unloaded pedaling can be used as a pathophysiological parameter of the vascular response of the exercising VLm in COPD patients.

There are some limitations to this study. The first limitation is the small number of study subjects. We studied male COPD patients with exercise intolerance, who could still undertake cycle exercise. We set the control subjects as the same gender to exclude possible systemic effects by hormonal factors. As for somewhat different body composition in females such as preferential lipid storage, neuro-endotrophic hormones such as leptin might be involved in the wide range of skeletal muscle metabolism [37]. Therefore, maybe, we could not generalize the findings to female COPD subjects. However, our observations provide a strong rationale for investigating the potential clinical relevance of muscle oxygenation in the pathophysiology of COPD. Future studies should be aimed at clarifying the relationship of muscle oxygenation dynamics and various neuro-endotrophic factors. In addition, we neither studied those with the same level of exercise capacity as healthy subjects (i.e. at-risk or stage I patients) nor those with symptoms of dyspnea too severe to allow exercise. COPD has a wide range of disease stages from mild to very severe [19]. Future studies should be aimed at clarifying differences of muscle oxygenation dynamics during exercise in different COPD disease stages. A second limitation is that we did not determine the relationship between muscle desaturation and muscle blood flow measured by vascular catheterization. Previous studies have shown that blood flow in exercising leg muscle is not decreased at the same power output during incremental cycle exercise in COPD patients compared with healthy subjects $[11,38]$. The data of vascular catheterization reflects total blood flow of the leg, and cannot differentiate between flow through the exercising and non-exercising muscle, whereas, NIRS evaluates local tissue oxygenation of the exercising muscle [39]. Similar to our findings, the muscle oxygenation signal of NIRS decreases steeply on incremental submaximal exercise in patients with heart failure, the mechanism for which is decreased cardiac output and systemically enhanced sympathetic nervous activity [40, 41]. We consider that, even if blood flow was not impaired, a steep decrease of $\mathrm{SmO}_{2}$ relative to the increase in workload would be explained by the findings that impairment of muscle oxygenation is related to pulmonary function impairments, and by the difference of measurement techniques of vascular catheterization and NIRS. We speculate that the factors contributing to impairment of muscle oxygenation in cardiopulmonary diseases are diverse, including ventilatory and gas exchange disorders of the alveolus in COPD $[2,3$, 42], decreased blood flow caused by cardiac impairment in heart failure [40, 41], and an activated sympathetic nervous system commonly found in both diseases [43].

\section{CONCLUSIONS}

Muscle oxygenation status during submaximal exercise is as severely impaired in COPD patients as in age-matched healthy subjects because of the same level of trough $\mathrm{SmO}_{2}$ despite lower peak workload in COPD patients than in healthy subjects. This finding leads to the important clinical insight that COPD patients experience anaerobic condition of muscle oxygenation quite easily during daily physical movement, and that such impairment degree of muscle oxygenation in COPD patients corresponds to that of submaximal workload for healthy subjects.

NIRS can monitor muscle oxygenation dynamics in a continual manner, the data of which is suitable for investigating the relations with various parameters of cardiopulmonary data obtained by exercise testing. In COPD patients, the decrease of $\mathrm{SmO}_{2}$ is correlated with the impairment of lung function such as EIH and airflow limitation caused by COPD. Furthermore, COPD patients who need to stop exercising below the AT level because of dyspnea were characterized by a shallower breathing pattern with a similar level of muscle deoxygenation compared with other COPD subgroups. NIRS can be of great assistance in elucidating complex pathophysiological mechanisms of skeletal muscle dysfunction in COPD.

\section{ACKNOWLEDGEMENTS}

The authors declare that they have no conflict of interest in this study. We thank Dr. Ryoji Maekura, vice-director of National Hospital Organization Toneyama National 
Hospital, for critical reading and helpful discussions of the manuscript.

\section{REFERENCES}

[1] Wasserman K, Hansen JE, Sue DY, Casaburi R, Whipp BJ. Principles of exercise testing and interpretation: including pathophysiology and clinical applications. $4^{\text {th }}$ ed. Baltimore: Lippincott Williams and Wilkins 2004.

[2] O'Donnell DE, Laveneziana P. Dyspnea and activity limitation in COPD: mechanical factors. COPD 2007; 4: 225-36.

[3] Barnes PJ. Chronic obstructive pulmonary disease. N Engl J Med 2000; 343: 269-80.

[4] Agusti AG, Noguera A, Sauleda J, Sala E, Pons J, Busquets X. Systemic effects of chronic obstructive pulmonary disease. Eur Respir J 2000; 21: 347-60.

[5] Agusti AG, Sauleda J, Miralles C, et al. Skeletal muscle apoptosis and weight loss in chronic obstructive pulmonary disease. Am J Respir Crit Care Med 2002; 166: 485-9.

[6] Engelen MP, Schols AM, Does JD, Gosker HR, Deutz NE, Wouters EF. Exercise-induced lactate increase in relation to muscle substrates in patients with chronic obstructive pulmonary disease. Am J Respir Crit Care Med 2000; 162: 1697-704.

[7] Gosker HR, van Mameren H, van Dijk PJ, et al. Skeletal muscle fibre-type shifting and metabolic profile in patients with chronic obstructive pulmonary disease. Eur Respir J 2002; 19: 617-25.

[8] Maltais F, LeBlanc P, Whittom F, et al. Oxidative enzyme activities of the vastus lateralis muscle and the functional status in patients with COPD. Thorax 2000; 55: 848-53.

[9] Whittom F, Jobin J, Simard PM, et al. Histochemical and morphological characteristics of the vastus lateralis muscle in patients with chronic obstructive pulmonary disease. Med Sci Sports Exerc 1998; 30: 1467-74.

[10] Kutsuzawa T, Shioya S, Kurita D, Haida M, Ohta Y, Yamabayashi $\mathrm{H}$. Muscle energy metabolism and nutritional status in patients with chronic obstructive pulmonary disease. $\mathrm{A}{ }^{31} \mathrm{P}$ magnetic resonance study. Am J Respir Crit Care Med 1995; 152: 647-52.

[11] Maltais F, Jobin J, Sullivan MJ, et al. Metabolic and hemodynamic responses of lower limb during exercise in patients with COPD. J Appl Physiol 1998; 84: 1573-80.

[12] Chance B, Borer E, Evans A, et al. Optical and nuclear magnetic resonance studies of hypoxia in human tissue and tumors. Ann N Y Acad Sci 1988; 551: 1-16.

[13] Quaresima V, Pizzi A, de Blasi R, Ferrari A, de Angelis M, Ferrari $\mathrm{M}$. Quadriceps oxygenation change during walking and running on a treadmill. Proc Soc Photo Opt Instrum Eng 1995; 2387: 249-56.

[14] Chuang ML, Ting H, Otsuka T, et al. Muscle deoxygenation as related to work rate. Med Sci Sports Exerc 2002; 34: 1614-23.

[15] DeLorey DS, Kowalchuk JM, Paterson DH. Relationship between pulmonary $\mathrm{O}_{2}$ uptake kinetics and muscle deoxygenation during moderate-intensity exercise. J Appl Physiol 2003; 95: 113-20.

[16] Grassi B, Hogan MC, Greenhaff PL, et al. Oxygen uptake onkinetics in dog gastrocnemius in situ following activation of pyruvate dehydrogenase by dichloroacetate. J Physiol 2002; 538: 195-207.

[17] Miura T, Takeuchi T, Sato H, et al. Skeletal muscle deoxygenation during exercise assessed by near-infrared spectroscopy and its relation to expired gas analysis parameters. Jpn Circ J 1998; 62: 649-57.

[18] Sue DY, Wasserman K, Moricca RB, Casaburi R. Metabolic acidosis during exercise in patients with chronic obstructive pulmonary disease. Use of the $\mathrm{V}$-slope method for anaerobic threshold determination. Chest 1988; 94: 931-8.

[19] Rabe KF, Hurd S, Anzueto A, et al. Global strategy for the diagnosis, management, and prevention of chronic obstructive pulmonary disease: GOLD executive summary. Am J Respir Crit Care Med 2007; 176: 532-55.

[20] Suzuki S, Takasaki S, Ozaki T, Kobayashi Y. A tissue oxygenation monitor using NIR spatially resolved spectroscopy. Proc Soc Photo Opt Instrum Eng 1999; 3597: 582-92.
[21] Grassi B, Quaresima V, Marconi C, Ferrari M, Cerretelli P. Blood lactate accumulation and muscle deoxygenation during incremental exercise. J Appl Physiol 1999; 87: 348-55.

[22] Agusti AGN, Salueda J, Noguera A, Busquets X. Mechanisms of systemic effects. In: Barns PJ, Ed. Choronic obstructive pulmonary disease: cellular and molecular mechanisms, Florida : Taylor and Francis 2005; pp. 425-45.

[23] Richardson RS, Sheldon J, Poole DC, Hopkins SR, Ries AL, Wagner PD. Evidence of skeletal muscle metabolic reserve during whole body exercise in patients with chronic obstructive pulmonary disease. Am J Respir Crit Care Med 1999; 159: 881-5.

[24] Maltais F, Simard AA, Simard C, Jobin J, Desgagnes P, LeBlanc P. Oxidative capacity of the skeletal muscle and lactic acid kinetics during exercise in normal subjects and in patients with COPD. Am J Respir Crit Care Med 1996; 153: 288-93.

[25] Austin KG, Mengelkoch L, Hansen J, Shahady E, Sirithienthad P, Panton L. Comparison of oxygenation in peripheral muscle during submaximal aerobic exercise, in persons with COPD and healthy, matched-control persons. Int J Chron Obstruct Pulmon Dis 2006; 1: 1467-75.

[26] Vogiatzis I, Athanasopoulos D, Stratakos G, et al. Exerciseinduced skeletal muscle deoxygenation in $\mathrm{O}_{2}$-supplemented COPD patients. Scand J Med Sci Sports 2008; 1: 467-75.

[27] Harms CA, Babcock MA, McClaran SR, et al. Respiratory muscle work compromises leg blood flow during maximal exercise. J Appl Physiol 1997; 82: 1573-83.

[28] Borghi-Silva A, Oliveira CC, Carrascosa C, et al. Respiratory muscle unloading improves leg muscle oxygenation during exercise in patients with COPD. Thorax 2008; 63: 910-5.

[29] Celli BR, Cote CG, Marin JM, et al. The body-mass index, airflow obstruction, dyspnea, and exercise capacity index in chronic obstructive pulmonary disease. N Engl J Med 2004; 350: 1005-12.

[30] Matsui S, Tamura N, Hirakawa T, Kobayashi S, Takekoshi N, Murakami E. Assessment of working skeletal muscle oxygenation in patients with chronic heart failure. Am Heart J 1995; 129: 690-5.

[31] Palange P, Forte S, Onorati $\mathrm{P}$, et al. Effect of reduced body weight on muscle aerobic capacity in patients with COPD. Chest 1998; 114: $12-8$.

[32] Okamoto T, Kanazawa H, Hirata K, Yoshikawa J. Evaluation of oxygen uptake kinetics and oxygen kinetics of peripheral skeletal muscle during recovery from exercise in patients with chronic obstructive pulmonary disease. Clin Physiol Funct Imaging 2003; 23: $257-62$.

[33] Saey D, Michaud A, Couillard A, et al. Contractile fatigue, muscle morphometry, and blood lactate in chronic obstructive pulmonary disease. Am J Respir Crit Care Med 2005; 171: 1109-15.

[34] Laughlin MH, Korthuis RJ, Duncker DJ, Bache RJ. Control of blood flow to cardiac and skeletal muscle during exercise. In: Rowell LB, Shepherd JT, Eds. Handbook of Physiology, Am Physiol Soc 1996; vol 12.

[35] Saltin B, Radegran G, Koskolou MD, Roach RC. Skeletal muscle blood flow in humans and its regulation during exercise. Acta Physiol Scand 1998; 162: 421-36.

[36] Nyberg M, Mortensen SP, Thaning P, Saltin B, Hellsten Y. Interstital and plasma adenosine stimulate nitric oxide and prostacyclin formation in human skeletal muscle. Hypertension 2010; 56: 1102-8.

[37] Andreas S, Anker SD, Scanlon PD, Somers VK. Neurohumoral activation as a link to systemic manifestations of chronic lung disease. Chest 2005; 128: 3618-24.

[38] Richardson RS, Leek BT, Gavin TP, et al. Reduced mechanical efficiency in chronic obstructive pulmonary disease but normal peak $\mathrm{V}_{\mathrm{O} 2}$ with small muscle mass exercise. Am J Respir Crit Care Med 2004; 169: 89-96.

[39] Hiroyuki H, Hamaoka T, Sako T, et al. Oxygenation in vastus lateralis and lateral head of gastrocnemius during treadmill walking and running in humans. Eur J Appl Physiol 2002; 87: 343-9.

[40] Belardinelli R, Barstow TJ, Nguyen P, Wasserman K. Skeletal muscle oxygenation and oxygen uptake kinetics following constant work rate exercise in chronic congestive heart failure. Am J Cardiol 1997; 80: 1319-24. 
[41] Wilson JR, Mancini DM, McCully K, Ferraro N, Lanoce V, Chance B. Noninvasive detection of skeletal muscle underperfusion with near-infrared spectroscopy in patients with heart failure. Circulation 1989; 80: 1668-74.

[42] Kurihara N, Fujimoto S, Terakawa K, Yamamoto M, Takeda T. Prediction of $\mathrm{PaO}_{2}$ during treadmill walking in patients with COPD. Chest 1987; 91: 328-32.
[43] Bratel T, Wennlund A, Carlstrom K. Impact of hypoxaemia on neuroendocrine function and catecholamine secretion in chronic obstructive pulmonary disease (COPD). Effects of long-term oxygen treatment. Respir Med 2000; 94: 1221-8.

Received: July 8, 2011

(c) Tateishi et al.; Licensee Bentham Open.

This is an open access article licensed under the terms of the Creative Commons Attribution Non-Commercial License (http: //creativecommons.org/licenses/by$\mathrm{nc} / 3.0 /$ ) which permits unrestricted, non-commercial use, distribution and reproduction in any medium, provided the work is properly cited. 